\title{
Structure of Horse Liver Alcohol Dehydrogenase
}

\author{
II. Heavy-atom Derivatives of Type A Crystals \\ B.- O. SÖDER B ER G, E. Z E P P E Z A UER, T. B O I V E, B. NOR D T RÖM \\ a n d C..I. B R Ä N DÉ N
}

Department of Chemistry, College of Agriculture, S.750 07 Uppsala 7, Sweden

\begin{abstract}
Three isomorphous heavy-atom derivatives of horse liver alcohol dehydrogenase have been prepared by forming complexes with $\mathrm{K}_{2} \mathrm{Pt}(\mathrm{CN})_{4}$ and $\mathrm{KAu}(\mathrm{CN})_{2}$. The platinum and the gold complexes bind to different characteristic sites, one per subunit. Centric projection data of the orthorhombic crystals were collected to $3 \AA$ resolution for the native enzyme, the two single derivatives, and the double derivative containing both platinum and gold. The heavy-atoms were located from difference Patterson and difference Fourier maps, and the parameters were refined by the method of least-squares. An analysis of the results of this refinement shows that these derivatives give a good phase-determination out to $3 \AA$ resolution. The mean figure of merit varies from 0.97 at low angles to 0.78 at high angles. The Kraut $R$-factor varies from 0.07 to 0.12 . The $E$-values, which are an estimated error in the structure-factors, are smaller than the heavy-atom contributions for all spacings and all derivatives.
\end{abstract}

$\mathbf{H}$ orse liver alcohol dehydrogenase (LADH) catalyses the oxidation of alcohol to aldehyde when in the presence of the cofactor nicotinamideadenine-dinucleotide. It is one of the many NAD-dependent dehydrogenases which are composed of two or four subunits, each of molecular weight between 35000 and 40000 . Of these a low resolution $X$-ray study has been reported for lactate dehydrogenase ${ }^{1}$ and preliminary X-ray data for glyceraldehyde-3phosphate dehydrogenase, ${ }^{2}$ soluble malate dehydrogenase, ${ }^{3}$ and liver alcohol dehydrogenase. ${ }^{4}$

We have earlier shown ${ }^{4,5}$ that $\mathrm{LADH}$ crystallizes with a crystallographic two-fold axis through the dimeric molecule in the absence of coenzyme. This crystal modification, type $A$, has orthorhombic symmetry, space-group $C 222_{1}$ with cell-dimensions $a=56 \AA, b=75 \AA$, and $c=181 \AA$.

The crystallographic molecular symmetry is lost in crystals where coenzyme molecules are bound to the enzyme.

We report here the preparation and investigation of heavy-atom derivatives of type A crystals. 


\section{PREPARATION OF CRYSTALS}

Purified homogeneous LADH, ${ }^{6}$ isoenzyme 3 , has been very generously provided to us by Dr. A. Akeson at the Nobel Medical Institute, Stockholm. Large crystals were grown as described earlier," except that 2-methyl-2,4-pentanediol was used as precipitant instead of ethanol. Dialysis bags or microdiffusion cells ${ }^{2}$ containing suitable crystals of type A were in general dialysed against a solution containing $20 \mathrm{ml} 0.05 \mathrm{M}$ tris/HCl, $\mathrm{pH}$ $8.4,17 \% \mathrm{v} / \mathrm{v}$ of 2-methyl-2,4-pentanediol and $10^{-3} \mathrm{M}$ of the appropriate heavy-metal salt. The enzyme crystals were usually dialysed against this heavy-atom containing solution for a month. Crystals containing $\mathrm{K}_{2} \mathrm{Pt}(\mathrm{CN})_{4}$ and the double derivative $\mathrm{K}_{2} \mathrm{Pt}(\mathrm{CN})_{4}+\mathrm{KAu}(\mathrm{CN})_{2}$ were, however, prepared by cocrystallization of $10^{-5} \mathrm{M}$ enzyme solution and $10^{-3} \mathrm{M} \mathrm{K}_{2} \mathrm{Pt}(\mathrm{CN})_{4}$ or $5 \times 10^{-4} \mathrm{M} \mathrm{K}_{2} \mathrm{Pt}(\mathrm{CN})_{4}+5 \times 10^{-4} \mathrm{M} \mathrm{KAu}(\mathrm{CN})_{2}$, respectively, in $0.05 \mathrm{M}$ tris/HCl, $\mathrm{pH}$ 8.4, using 2-methyl-2,4-pentanediol as precipitant.

When we started to try various heavy-metal salts we very soon found that almost any - SH reagent denatured the enzyme crystals. This is not very surprising in view of the fact that the enzyme molecule contains 28 cysteines, two of which are very reactive. ${ }^{8}$ We thus had to look for heavy-metal complexes which did not react with - SH groups and which were soluble at $\mathrm{pH}$ 8.4. A survey of the literature showed that some of the heavy transition metal cyanide complexes might be suitable. We were fortunate enough to find that $\mathrm{Pt}(\mathrm{CN})_{4}{ }^{2-}$ and $\mathrm{Au}(\mathrm{CN})_{2}{ }^{-}$bound to the enzyme at different single sites giving good isomorphous derivatives. It was also possible to prepare the double derivative containing both $\mathrm{Pt}(\mathrm{CN})_{4}^{2-}$ and $\mathrm{Au}(\mathrm{CN})_{2}^{-}$.

\section{COLLECTION AND MEASUREMENT OF INTENSITIES}

Crystals of suitable size $(1.0 \times 0.3 \times 0.15 \mathrm{~mm})$ were mounted at $+4^{\circ} \mathrm{C}$ in the usual way in glass capillaries in equilibrium with their mother liquor. Since these crystals have three centric projections, we decided to do the analysis of our heavy-atom derivatives from high-resolution projection data. 15.5 degrees precession photographs corresponding to a resolution of $3 \AA$ of the $h 0 l, 0 k l$, and $h k 0$ layers were taken at $+4^{\circ} \mathrm{C}$ with $\mathrm{CuK} \alpha$-radiation.
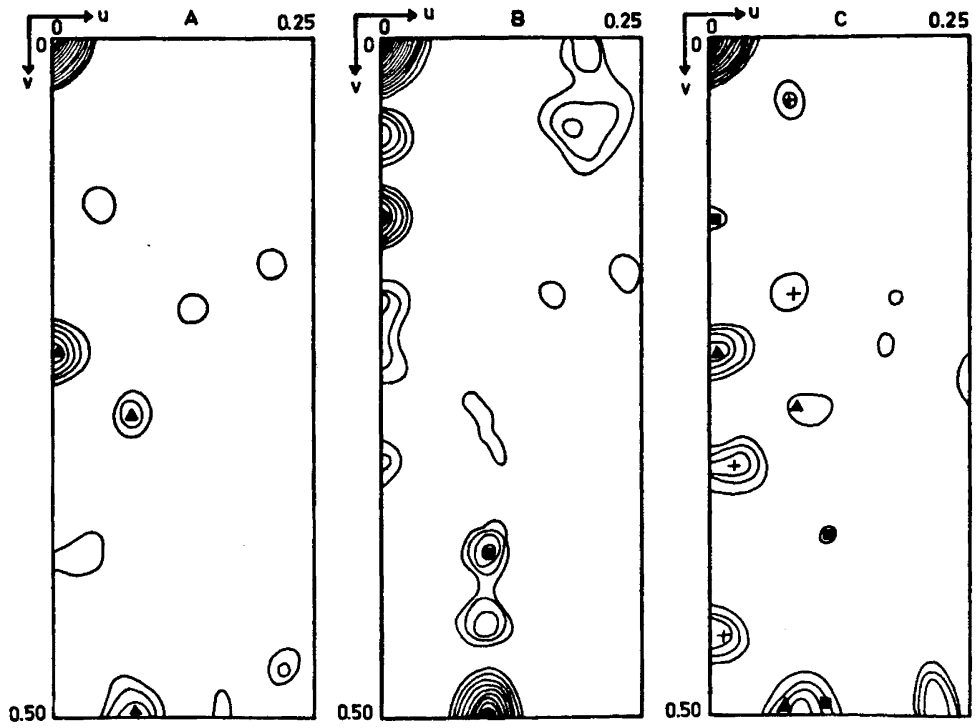

Fig. 1. Difference Patterson projections $P(u, v)$ of heavy-atom derivatives of LADH. (A) $\mathrm{K}_{2} \mathrm{Pt}(\mathrm{CN})_{4} \cdot$ (B) $\mathrm{KAu}(\mathrm{CN})_{2} \cdot$ (C) $\mathrm{K}_{2} \mathrm{Pt}(\mathrm{CN})_{4}+\mathrm{KAu}(\mathrm{CN})_{2}$.

Acta Chem. Scand. 24 (1970) No. 10 
Approximately $90 \%$ of the possible reflexions could be measured to this resolution. Each crystal lasted for about $25 \mathrm{~h}$ irradiation without any measurable damage. Four different exposure times were used for each layer, and the data were recorded on Ilford Industrial G X-ray film.

The intensities were measured as peak intensities on a Joyce-Loebl recording microdensitometer. The symmetry elements of space-group $C 222_{1}$ allow the intensity of each independent reflexion of the centric projections to be determined by four measurements on each film. Approximately 2000 reflexions were measured for each compound.

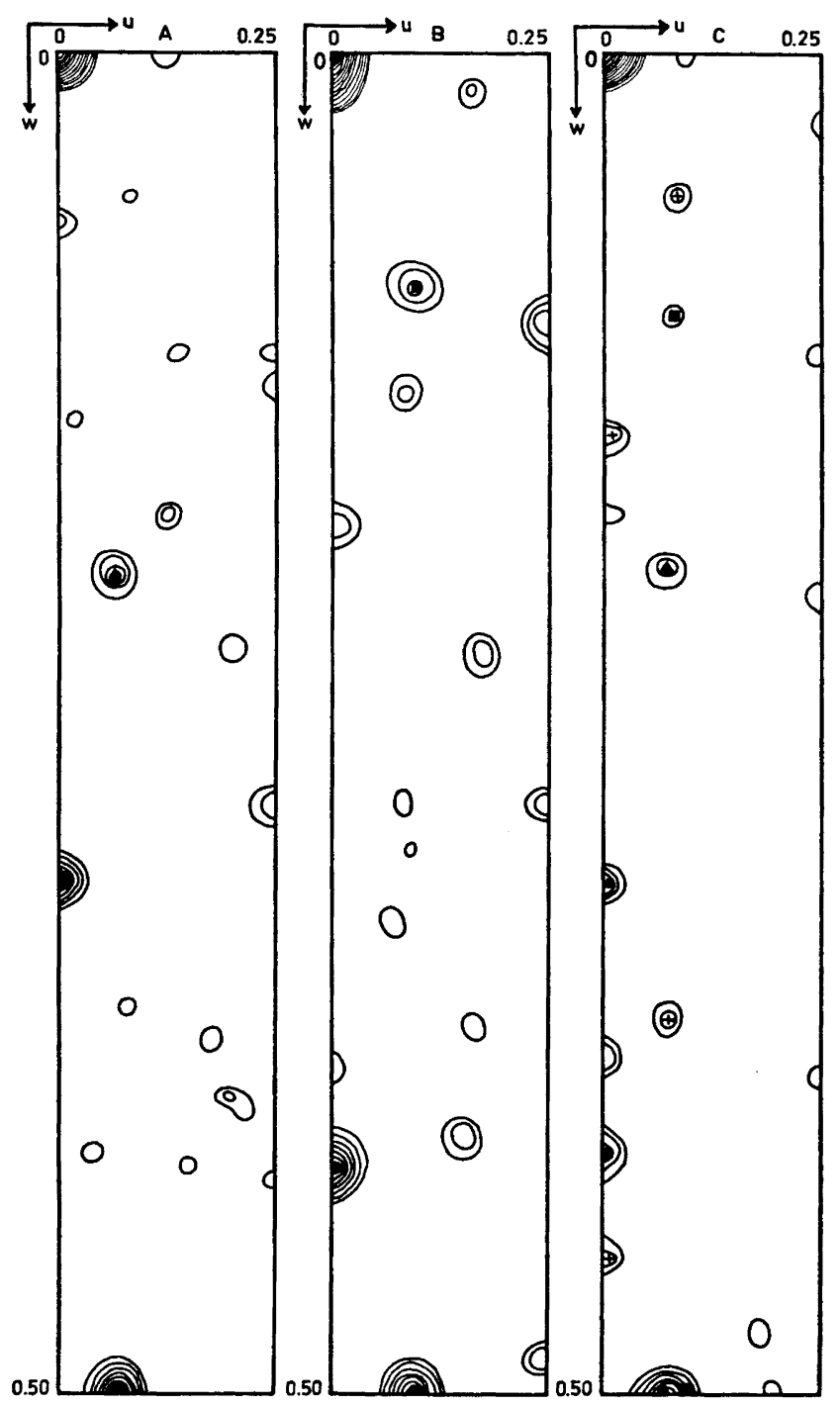

Fig. 2. Difference Patterson projections $P(u, w)$ of heavy-atom derivatives of LADH. (A) $\mathrm{K}_{2} \mathrm{Pt}(\mathrm{CN})_{4}$. (B) $\mathrm{KAu}(\mathrm{CN})_{2}$. (C) $\mathrm{K}_{2} \mathrm{Pt}(\mathrm{CN})_{4}+\mathrm{KAu}(\mathrm{CN})_{2}$.

Acta Chem. Scand. 24, (1970) No. 10 
Lorentz and polarization corrections were applied to the mean value of these four measurements.

Data have been collected for the native enzyme, two single derivatives containing $\mathrm{K}_{\mathbf{2}} \mathrm{Pt}(\mathrm{CN})_{4}$ and $\mathrm{KAu}(\mathrm{CN})_{2}$, respectively, and the double derivative from these two heavy metal complexes.

\section{DETERMINATION AND REFINEMENT OF HEAVY-ATOM PARAMETERS}

The heavy-atom positions were determined from difference Patterson and difference Fourier maps. The platinum and the gold sites were easily located from difference Patterson projections $P(u, v)$ and $P(u, w)$ of the singly substituted derivatives (Figs. 1 and 2). There was no indication of more than one site per derivative in these maps. The correct relative origin choice was deduced from all three difference Patterson projections of the double derivative $\mathrm{K}_{2} \mathrm{Pt}(\mathrm{CN})_{4}+\mathrm{KAu}(\mathrm{CN})_{2}$, and as a further check Rossmann-type correlation functions ${ }^{10}$ of the platinum derivative versus the gold derivative were calculated in two projections.

In order to check for minor heavy-atom sites we computed difference Fourier projections of the three derivatives (Figs. 3-4) using phase information for each derivative from the remaining two derivatives. No indication of minor sites was found in any derivative. Although extra peaks appear

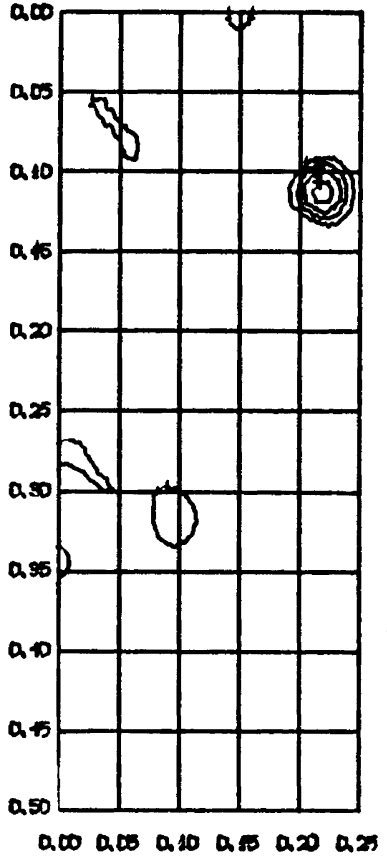

DF PT

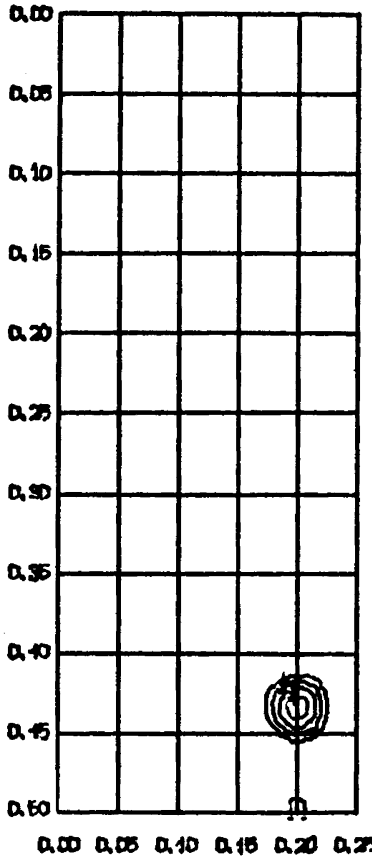

DF AU

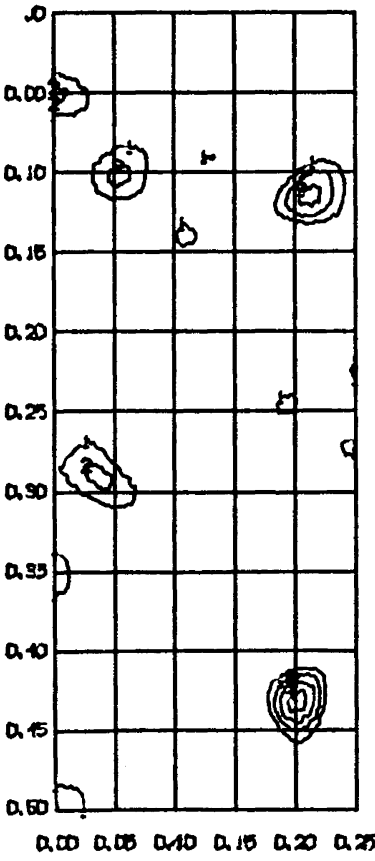

DF PTAU HKO

Fig. 3. Difference Fourier projections $\phi(x, y)$ of heavy-atom derivatives of LADH. 


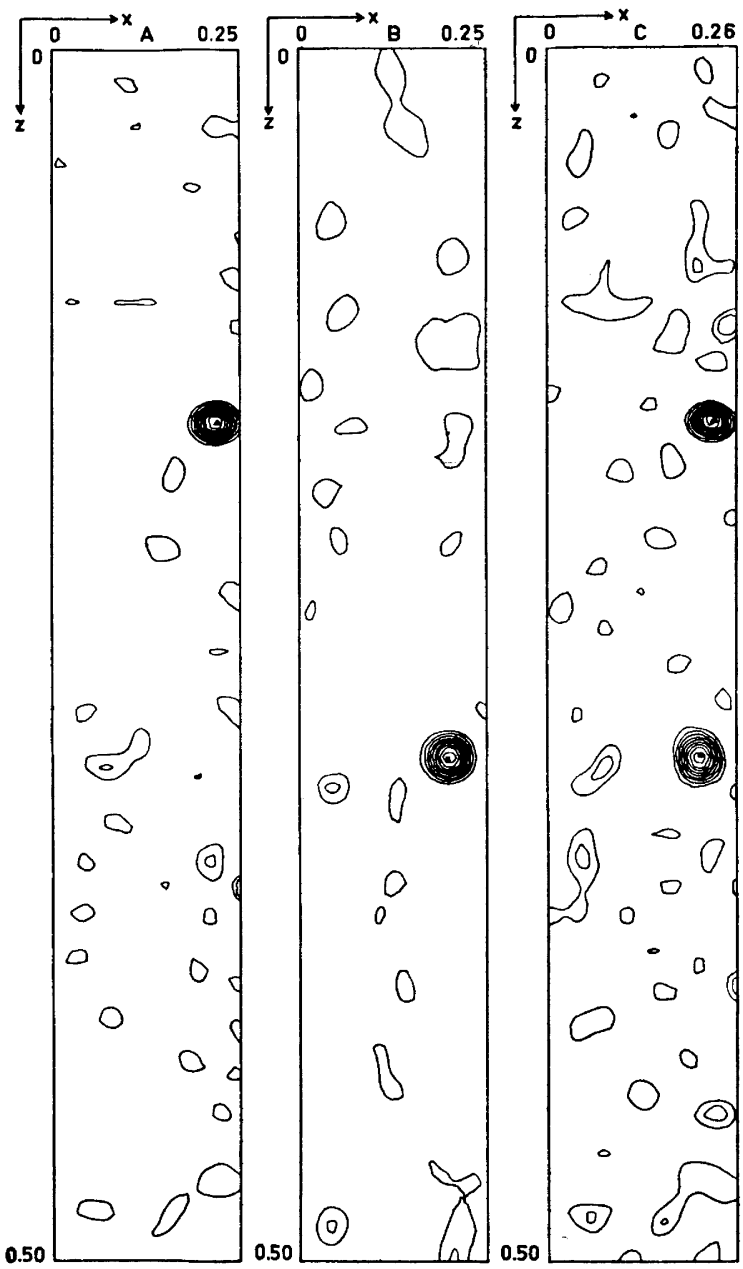

Fig. 4. Difference Fourier projections $\phi(x, z)$ of heavy-atom derivatives of LADH. (A) $\mathrm{K}_{2} \mathrm{Pt}(\mathrm{CN})_{4} \cdot(\mathrm{B}) \mathrm{KAu}(\mathrm{CN})_{2} \cdot(\mathrm{C}) \mathrm{K}_{2} \mathrm{Pt}(\mathrm{CN})_{4}+\mathrm{KAu}(\mathrm{CN})_{2}$.

in some $x y$-projections there are no corresponding peaks in the $x z$-projections. Most of the $x y$-maps have shown a fairly high background, and in some cases extra peaks occur probably due to the very long axis of projection, $181 \AA$, and the fairly small number of independent reflexions in this projection. We cannot exclude, however, that the final three-dimensional analysis will reveal the existence of minor heavy-atom sites.

The heavy-atom parameters has been refined by the method of least-squares using a programme written by one of us, B.-O. S. The main principles of this programme are the same as those described by Dickerson and Weinzierl, ${ }^{11}$

Acta Chem. Scand. 24 (1970) No. 10 
and which have been used in the work on carboxypeptidase ${ }^{12}$ and haemoglobin. ${ }^{13}$ Alternate cycles of sign determination and refinement of parameters were performed. Merged $h k 0$ and $h 0 l$ data were used in the refinement.

Positional parameters and occupancies of the heavy-atoms as well as two scale-factors for each derivative, one for each layer, were refined. The isotropic temperature factor $B$ has so far been fixed to a value of 30.0 . This value was found from a Wilson-plot of the observed $h 0 l$ platinum differences to $2.5 \AA$ resolution. The absolute scale has been adjusted, so that the occupancy of the platinum site is 78 electrons in the singly substituted Pt-derivative. The final parameters are given in Table 1.

Table 1. Final heavy-atom parameters. The $B$-values have been kept at constant values during the refinement.

\begin{tabular}{|c|c|c|c|c|c|c|c|c|c|c|}
\hline $\begin{array}{c}\text { Deriva- } \\
\text { tive }\end{array}$ & $\begin{array}{c}\text { Heavy } \\
\text { atom }\end{array}$ & $\begin{array}{l}\text { Occu- } \\
\text { pancy }\end{array}$ & $x$ & $y$ & $z$ & $B$ & $E_{\mathbf{j}}$ & $R_{\mathrm{S}}$ & $R_{\mathbf{K}}$ & $\begin{array}{l}\text { No. of } \\
\text { reflex- } \\
\text { ions }\end{array}$ \\
\hline 1 & $\mathbf{P t}$ & 78.0 & 0.2207 & 0.1131 & 0.1538 & 30 & 132 & 0.49 & 0.09 & 348 \\
\hline 2 & $\mathrm{Au}$ & 73.2 & 0.2987 & 0.0631 & 0.2077 & 30 & 105 & 0.45 & 0.07 & 307 \\
\hline \multirow[t]{2}{*}{3} & $\mathrm{Pt}$ & 45.8 & 0.2185 & 0.1147 & 0.1538 & 30 & 122 & 0.51 & 0.07 & 290 \\
\hline & $\mathbf{A u}$ & 47.8 & 0.2969 & 0.0649 & 0.2083 & 30 & & & & \\
\hline
\end{tabular}

Criteria which have been used to follow the refinement and to assess the usefulness of the derivatives for phase-determination are summarized in Table 2 as a function of interplanar spacing. The mean figure of merit for the complete set of data varies from 0.97 at low angles to 0.78 at high angles, which is very satisfactory. The overall $R$-values which are listed in Table 1 are slightly better than those obtained for example on cytochrome $c .^{14}$ The $E$-values, which are an estimated error in $F_{\text {HP }}$, are smaller than the observed heavy-atom contribution for all spacings and all three derivatives, which is a strong indication that all derivatives give meaningful phase-information to $3 \AA$ resolution. From the analysis of the results of this refinement we can thus conclude that there is strong hope that these derivatives should give a sufficiently accurate phase-determination to $3.0 \AA$ resolution to produce an interpretable three-dimensional electron density map.

Acknowledgements. We wish to thank Prof. H. Theorell and Dr. A. Åkeson for generous supplies of purified enzyme and for many valuable discussions. We also wish to express our gratitude to Prof. I. Lindqvist and Dr. M. Zeppezauer for their stimulating interest in this work.

We are indebted to Mrs. E. Berthagen and Miss A.-B. Pettersson for skilful technical assistance,

This work has been supported by grant 2767 from the Swedish Natural Science Research Council, grant B69-11X-2196-03 from the Swedish Medical Research Council, and by grants from Knut and Alice Wallenberg Foundation, and Magnus Bergvall Fund. Grants for computing facilities were provided from the National Swedish Office for Administrative Rationalization and Economy. These grants are gratefully acknowledged. 


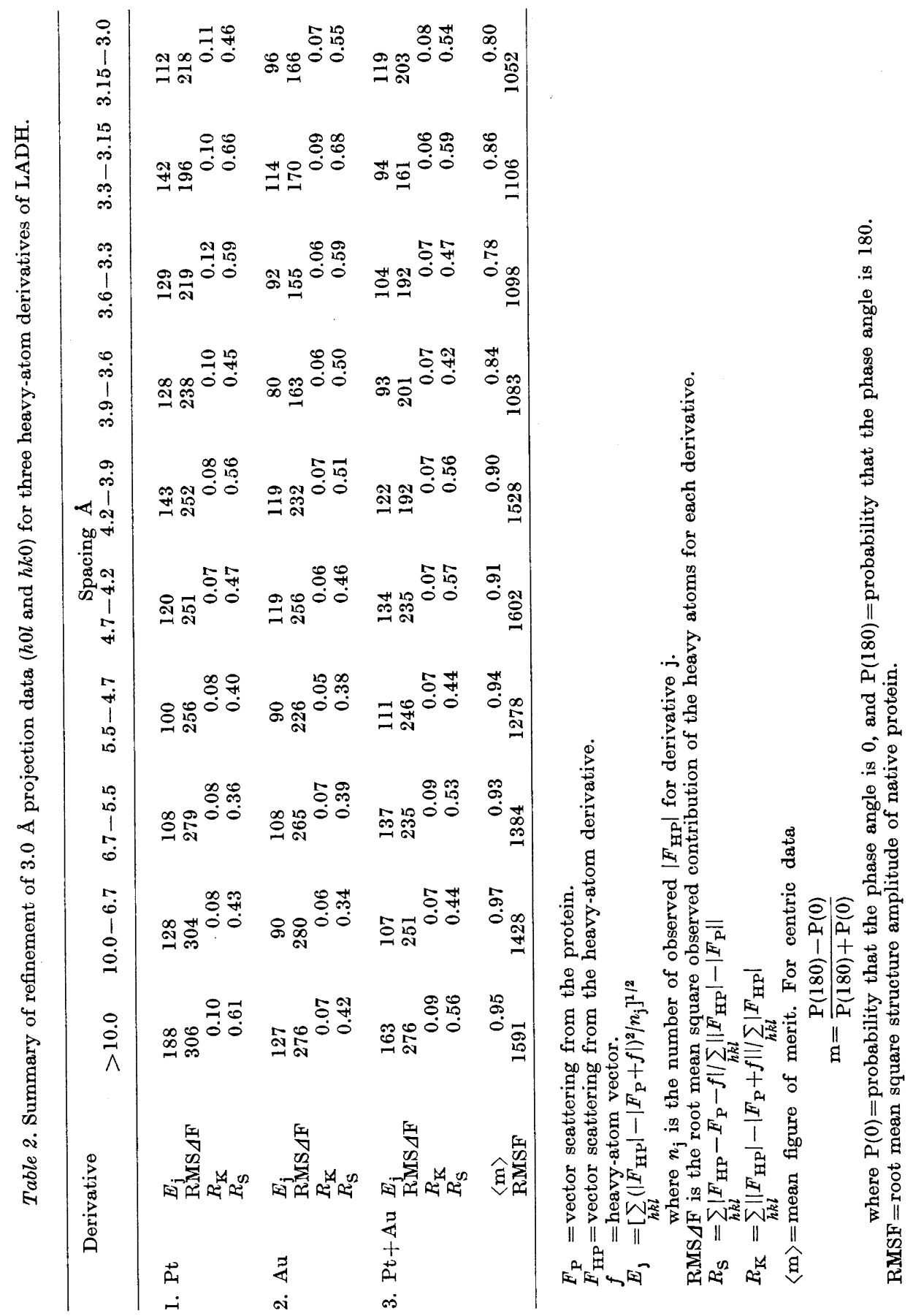

Acta Chem. Scand. 24 (1970) No. 10 


\section{REFERENCES}

1. Adams, M. J., Haas, D. J., Jeffery, B. A., McPherson, Jr., A., Mermall, H. L., Rossmann, M. G., Schevitz, R. W. and Wonacott, A. J. J. Mol. Biol. 41 (1969) 159.

2. Watson, H. C. and Banaszak, L. J. Nature 204 (1964) 918.

3. Banaszak, L. J. J. Mol. Biol. 22 (1966) 389.

4. Zeppezauer, E., Söderberg, B.-O., Brändén, C.-I., Åkeson, A. and Theorell, H. Acta Chem. Scand. 21 (1967) 1099.

5. Brändén, C.-I. Arch. Biochem. Biophys. 112 (1965) 215.

6. Pietruszko, R., Ringold, J., Li, T.-K., Vallee, B. L., Åkeson, A. and Theorell, H. Nature 221 (1969) 440.

7. Zeppezauer, M., Eklund, H. and Zeppezauer, E. S. Arch. Biochem. Biophys. 126 (1968) 564.

8. Yonetani, T. and Theorell, H. Arch. Biochem. Biophys. 99 (1962) 433.

9. Dawkins, P. D., Gould, B. J., Sturman, J. A. and Smith, J. H. J. Pharm. Pharmacol. 19 (1967) 355.

10. Rossmann, M. G. Acta Cryst. 13 (1960) 221.

11. Dickerson, R. E. and Weinzierl, J. E. Acta Cryst. B 24 (1968) 997.

12. Ludwig, M. L., Hartsuck, J. A., Steitz, T. A., Muirhead, H., Coppola, J. C., Reeke, G. N. and Lipscomb, W. N. Proc. Natl. Acad. Sci. U.S. 57 (1967) 511.

13. Perutz, M. F., Muirhead, H., Cox, J. M., Goaman, L. C. G., Mathews, F. S., McGandy, E. L. and Webb, L. E. Nature 219 (1968) 29.

14. Dickerson, R. E., Kopka, M. L., Borders, Jr., C. L., Varnum, J., Weinzierl, J. E. and Margoliash, E. J. Mol. Biol. 29 (1967) 77.

Received April 23, 1970. 